\title{
Study on concentrating primary reverse osmosis retentate by direct contact membrane distillation
}

\author{
Dan Qu, Jun Wang, Bin Fan, Zhaokun Luan*, Deyin Hou \\ State Key Laboratory of Environmental Aquatic Chemistry, Research Center for Eco-Environmental \\ Sciences, The Chinese Academy of Sciences, Beijing100085, China \\ Tel/Fax:+86-10-62849150; email: luanzk@rcees.ac.cn
}

Received 1 June 2007; accepted 24 August 242008

\begin{abstract}
The direct contact membrane distillation (DCMD) applied for the concentration of the primary reverse osmosis (PRO) retentate was presented in the paper. All the experiments were carried out using the self-made hydrophobic polyvinylidene fluoride (PVDF) membranes. The DCMD process (permeate flux and conductivity) and membrane fouling phenomenon were investigated. Three kinds of PRO retentate (direct PRO retentate, silica bearing PRO retentate, and iron and manganese bearing PRO retentate) were used in the experiments. During the whole period of investigation, the membranes were found to be thermally stable and good separation characteristics. The RO was fed with the tap water with the recovery of 50\%. After DCMD process, the whole water recovery can be significantly enhanced to $98.8 \%$. Membrane fouling was observed during the process. Membrane clogging caused by the formed deposit $\left(\mathrm{CaCO}_{3}, \mathrm{CaSO}_{4}\right.$, and silicate) was the main reason of the membrane efficiency reduction. It was found that $\mathrm{CaCO}_{3}$ formed at first during the process, and can be alleviated even eliminated by acidification. When the PRO retentate was concentrated a high level, $\mathrm{CaSO}_{4}$ formed and caused a sharp decline of module efficiency. During the DCMD process of silica bearing PRO retentate, silica may co-precipitate with soluble metals to form silicate at alkaline solutions while colloid silica may form at acidic solutions. The influence of iron and manganese is not significant.
\end{abstract}

Keywords: Direct contact membrane distillation; Reverse osmosis; Recovery; Membrane fouling

\section{Introduction}

Reverse osmosis (RO) has been widely used in the preparation of industrial pure water and other fields such as chemical engineering and environmental engineering. At present, the

*Corresponding author. recovery of primary reverse osmosis (PRO) is usually kept at $50-75 \%$. In the above range of water recovery, the retentate volume is significant and thus represents a loss of valuable water resource and a major disposal challenge. Currently the available methods to improve RO recovery are using water soluble polymeric antiscalants. Even though, the recovery is still kept at 
a low level about $75-85 \%$ [1]. Other pretreatment methods such as accelerated precipitation softening (APS) for secondary or higher levels of RO process were also investigated. It was reported that a laboratory bench-scale system for evaluating enhanced water recovery via RO desalting (50-75\%), followed by APS treatment and subsequently secondary RO desalting to achieve total recovery of 95-98\% [2]. Here, a hydrophobic membrane process - membrane distillation (MD) was considered.

MD is a thermally driven process that involves transport of water vapor through a porous hydrophobic membrane [3]. During MD of solutions with non-volatile solutes, only water vapor can be transferred through the membrane, so theoretically the MD process enables the production of pure water from natural water. In addition, it is less dependent on the initial salinity of the feed as well as a higher salt rejection ratio. And it is less demanding in membrane's mechanical strength. Thus, MD is often proposed for desalination [4-6] and other applications such as the concentration of juice and the separation of volatile metabolites [7, 8].

The principal obstacle in MD process is associated with membrane fouling and wettability [9]. The latter phenomenon is responsible not only for a decline of the plant efficiency, but also a damage of the module over a short time. The feed type has a considerable influence on membrane fouling. The PRO retentate with low content of organic compounds decreased the possibility of membrane wettability. Thus, it is possible to enhance water recovery by MD process. Meanwhile, the industrial pure water is obtained. It is significant in economizing water resource.

However, the PRO retentate contains high content of inorganic ions such as $\mathrm{Ca}^{2+}, \mathrm{HCO}_{3}^{-}$, $\mathrm{SO}_{4}^{2-}, \mathrm{SiO}_{3}^{2-}$ and so on. At higher temperature and levels of recovery, the concentration of ions on the membrane feed-side may exceed the solubility limit such as $\mathrm{CaCO}_{3}$ and $\mathrm{CaSO}_{4}$, which may lead to permeate flux decline and even wetting phenomenon. During pressure-driven membrane process (NF and RO), the $\mathrm{CaCO}_{3}$ and $\mathrm{CaSO}_{4}$ scaling potential assessment has been described in many papers. Sheikholeslami [10] used the scaling potential index (SPI) to assess the scaling potential for sparing soluble salts in $\mathrm{RO}$ and NF units. Samir et al. [11] used molar ratio as a tool for prediction of scaling potential in RO systems. Sangho Lee et al. [12] also discussed the scale formation mechanism in various NF modules. However, $\mathrm{CaCO}_{3}$ and $\mathrm{CaSO}_{4}$ scaling was just mentioned to be found during MD process [1315]. Few discussions about the scaling potential and different scaling properties were presented. Chernyshov et al. [16] had ever used Lias and Govind method to model temperature and salt concentration distribution in membrane distillation feed channel and concluded that if the solubility of salt decreases with temperature, maximum supersaturation can occur in the bulk of the flow rater than at the membrane surface. It can be used to explain the $\mathrm{CaCO}_{3}$ and $\mathrm{CaSO}_{4}$ scaling phenomenon during MD process. Recently, Fei He et al. [17] analyzed the $\mathrm{CaSO}_{4}$ scaling potential in hollow fiber membrane in terms of the saturation index profiles during the crossflow DCMD.

Silica was considered to be a problemic foulant during membrane process. In naturally occurring waters, silica is weakly ionized and existed as monosilicic acid while at higher concentrations, monosilicic acid polymerizes to form lager polysilicic acids, the larger of which are of a colloidal size. In neutral or slightly alkaline solutions, silica can also co-precipitate with soluble metals forming silicate [18]. Sheikholeslami et al. had done a lot of works on silica fouling during RO process [19-23]. Iron and manganese are also the two common ions in natural water, and it was reported that membrane fouling with $\mathrm{Fe}$ $(\mathrm{OH})_{3}$ occurs both in the strongly acidic or alkaline medium during RO process [24]. So, all the inorganic ions mentioned above may limit the 
module efficiency and their fouling mechanism during the MD process should be investigated.

Direct contact membrane distillation (DCMD) is one of the four basic configurations of $\mathrm{MD}$, in which the feed and the permeate are directly separated by the membrane. And DCMD is considered to be the most simple, economic and efficient configurations. Thus, in the present paper, DCMD was applied for concentrating the PRO retentate to enhance the water recovery. Three different kinds of $\mathrm{PRO}$ retentate (direct PRO retentate, silica bearing PRO retentate, and iron and manganese bearing PRO retentate) were used in the experiments. DCMD performance in terms of flux and conductivity stability was observed throughout the whole experiment periods. And also membrane fouling was observed during the process.

\section{Experimental}

\subsection{Membrane modules and the DCMD unit}

The membrane module was made by a polyester tube and two UPVC T-tubes. The outside/ inside diameters of the module were $20 \mathrm{~mm} /$ $15 \mathrm{~mm}$ and the effective length of the module was $100 \mathrm{~mm}$. The module was equipped with 50 hydrophobic hollow fiber PVDF membranes. The outside/inside diameters of the membrane were $1 \mathrm{~mm} / 0.6 \mathrm{~mm}$, respectively. The porosity, average pore radius and the membrane thickness were $80 \%, 0.15 \mu \mathrm{m}$ and $0.2 \mathrm{~mm}$, respectively. The total efficient area of the module was calculated for the internal diameter of hollow fiber membrane and amounted to $94.20 \mathrm{~cm}^{2}$.

The experimental setup is shown in Fig. 1. The DCMD installation was consisted of two thermostatic cycles, the feed one and the permeate one, which were connected to the membrane module. Both the feed and the permeate were pumped from the bottom to the upper part of the module assembled in a vertical position. The feed flowed inside the capillaries, whereas the permeate

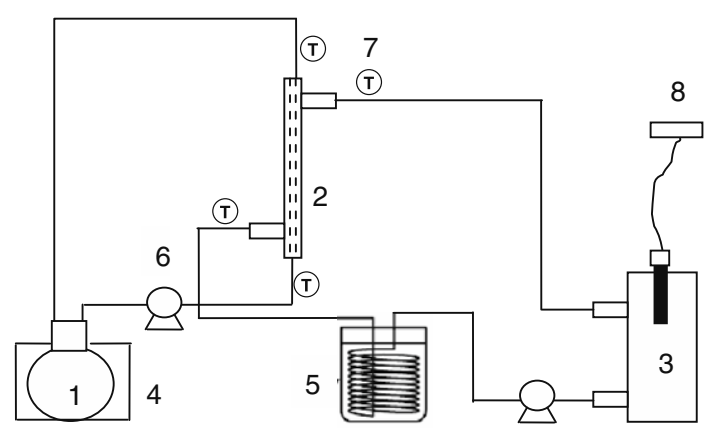

Fig. 1. Membrane distillation setup: (1) feed reservoir; (2) membrane module; (3) permeate reservoir; (4) water bath; (5) cooling coil; (6) pump; (7) thermometer; and (8) conductivity monitor.

flowed through the intertubular space. Two magnetic pumps were used to provide the flow of the feed preheated in the thermostatic bath and the permeate cooled through the cooling coil. There were 4 thermometers equipped on both the inlet and the outlet of the feed and the permeate sides. The permeate flux was measured by the overflow volume of the permeate reservoir.

\subsection{The primary reverse osmosis retentate}

The PRO retentate was used as the basic feed in the presented paper. The RO system was one unit of the direct drinking water preparation system, which consisted of ozone oxidation, catalyze oxidation and active carbon filtration before the RO system to get rid of organic compounds. No antiscalants were used. So the total organic carbon (TOC) analysis revealed that the PRO retentate contained less than $1 \mathrm{mg} \mathrm{L}^{-1}$ of the TOC. The RO was supplied with the tap water with the recovery of $50 \%$. The conductivity of PRO retentate varied from 980 to $1200 \mu \mathrm{s} \mathrm{cm}^{-1}$. The $\mathrm{pH}$ was about 7.90 in average. The average concentrations of the major ions were as follows: $\mathrm{Ca}^{2+} 376.00 \mathrm{mg} \mathrm{L}^{-1}, \mathrm{Mg}^{2+} 203.00 \mathrm{mg} \mathrm{L}^{-1}$, $\mathrm{Cl}^{-} 56.75 \mathrm{mg} \mathrm{L}^{-1}, \mathrm{SiO}_{3}^{-} 11.22 \mathrm{mg} \mathrm{L}^{-1}, \mathrm{HCO}_{3}^{-}$ $9.25 \mathrm{mmol} \mathrm{L}{ }^{-1}$ and $\mathrm{CO}_{3}^{2-} 0.35 \mathrm{mmol} \mathrm{L} \mathrm{L}^{-1}$. Additional $\mathrm{Na}_{2} \mathrm{SiO}_{3} .9 \mathrm{H}_{2} \mathrm{O}, \quad \mathrm{FeCl}_{2} \cdot 6 \mathrm{H}_{2} \mathrm{O}$ and $\mathrm{MnCl}_{2} \cdot 4 \mathrm{H}_{2} \mathrm{O}$ were added in the PRO retentate 
for special experimental needs. All the reagents were analytical grade.

\subsection{DCMD experiments}

New modules were used for each experimental series. During each series, the DCMD installation worked non-stop until the permeate flux declined significantly and then rinsed the module with $2 \%$ $\mathrm{HCl}$. After rinsing the module, other correlative experiments were performed on the same module. The initial flow rate of the feed was $0.60 \mathrm{~m} \mathrm{~s}^{-1}$, whereas the permeate flow rate was $0.18 \mathrm{~m} \mathrm{~s}^{-1}$ during all the experiments. And the inlet temperature of the feed and the permeate were $50 \pm 1{ }^{\circ} \mathrm{C}$ and $20 \pm 1^{\circ} \mathrm{C}$, respectively.

\subsection{Analysis methods}

The permeate conductivity was measured by an online conductivity monitor. The concentration of $\mathrm{Ca}^{2+}$ was determined with EDTA titration, and the concentration of $\mathrm{SO}_{4}^{2-}$ was measured by the spectrophotometer (DR/4000U, HACH, USA). The analysis for soluble silica was carried out using molybdosilicate method and the spectrophotometer. The morphology and the composition of the fouling matter was studied using scanning electron microscopy (S-3000N, HITACHI, Japan) coupled with energy dispersion spectrometry (Genesis, EDAX, USA). The membrane samples were made by liquid nitrogen and then dried in the oven at $50^{\circ} \mathrm{C}$. Then the samples were sputter coated with gold and examined. The accelerating voltage was $5 \mathrm{kV}$.

\section{Results and discussion}

\subsection{DCMD process of the PRO retentate}

The experimental results shown in Fig. 2 (stage I) demonstrated the direct application of the PRO retentate as a feed. At the initial stage of the experiments, an increase of permeate flux from $10.50 \mathrm{~kg} \mathrm{~m}^{-2} \mathrm{~h}^{-1}$ to $11.40 \mathrm{~kg} \mathrm{~m}^{-2} \mathrm{~h}^{-1}$ was observed, just as reported in other works $[9,25]$. There were two explanations based on the PP membrane experiments for the initial flux increase. One reason may be associated with a change of the membrane morphology [25]. It

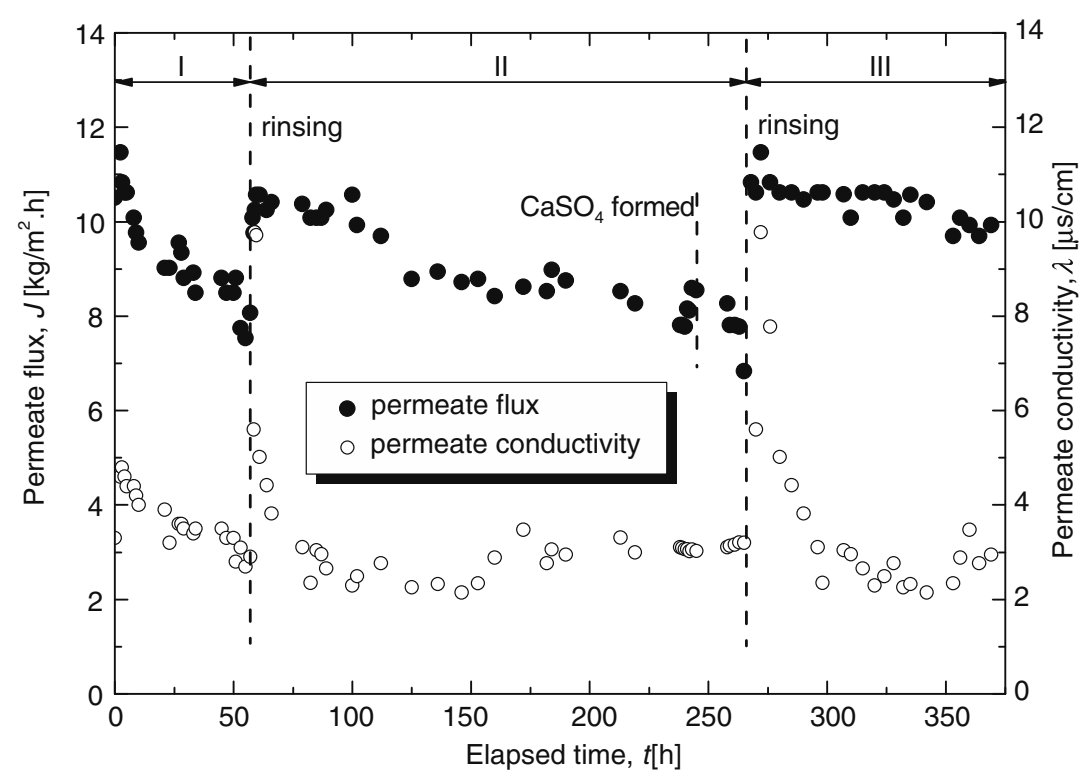

Fig. 2. Variation of the efficiency during the DCMD process. 
was reported that a significant increase of membrane pores were observed after the water contact experiments, which lead to the reduction of resistance of the vapor transfer across the membrane. Another reason was the asymmetrical structure of the membrane reported by Gryta [9]. It was pointed that the pores on the membrane surface were lager, what may lead pores to be filled with water. It caused a decrease of thickness of the gas diffusion paths and consequently the DCMD efficiency was increased.

The SEM images of membranes are shown in Fig. 3. The morphology of the PVDF membrane was uniform with the finger-like pores outside and the sponge structure in the center. However, the pores on the inner membrane surface were not obvious at a low magnify factor $(500 \times)$ (Fig. $3 \mathrm{a}_{1}$ ), while the sponge structure was clear in sight (Fig. 3 $b_{1}$ ). At a larger magnify factor $(2000 \times)\left(\right.$ Fig. $\left.3 a_{2}\right)$, the pores in the membrane surface come into sight with a small diameter. Obviously, the pores on the membrane surface were much smaller than the sponge pores, so the reason of flux increase was not related to the larger pores on the membrane surface. The observations performed with new membrane (Fig. $3 a_{2}$ and $b_{2}$ ) and the membrane collected from the module after $5 \mathrm{~h}$ of the MD performance (Fig. $3 a_{3}$ and $b_{3}$ ) did not reveal any significant differences in the morphology (both the surface and the cross-section). However, a slight increase of pore size, difficult to assess visually, can lead the reduction of the resistances of vapor diffusion across the membrane and the permeate flux may increase. The permeate conductivity kept decreasing during the process and it indicated

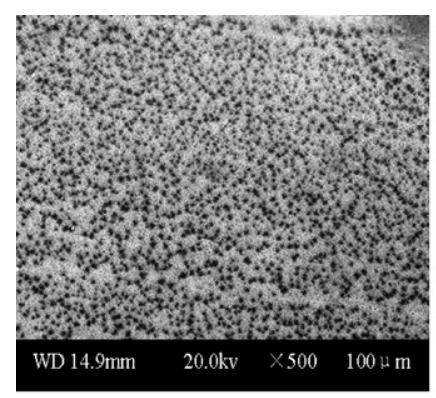

$\left(a_{1}\right)$

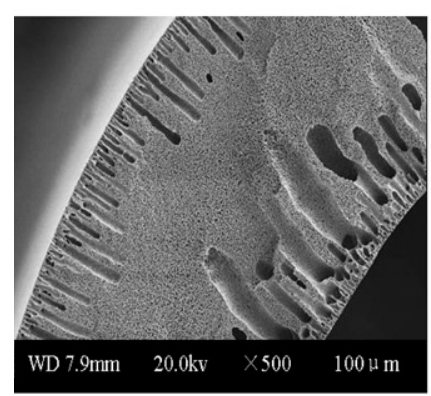

$\left(b_{1}\right)$

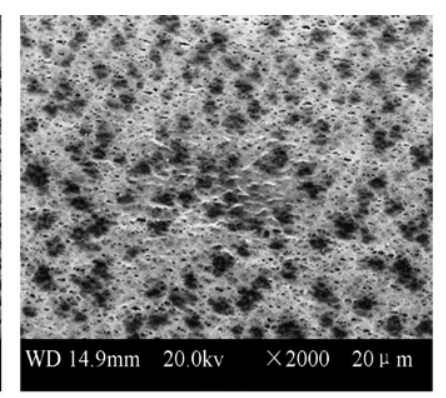

$\left(\mathrm{a}_{2}\right)$

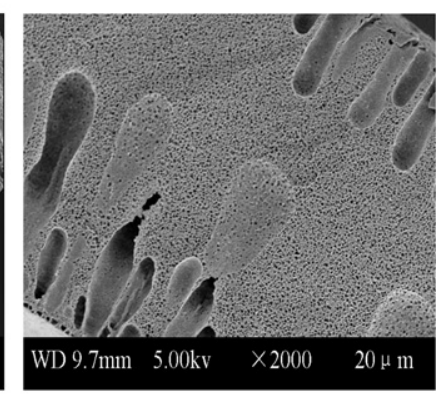

$\left(b_{2}\right)$

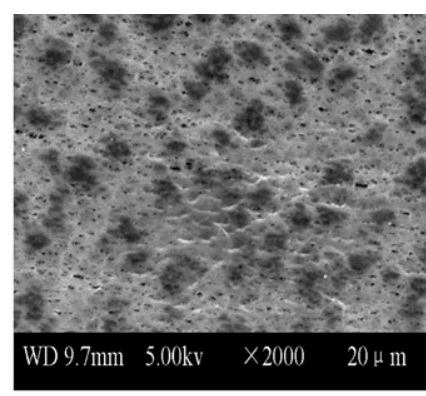

$\left(a_{3}\right)$

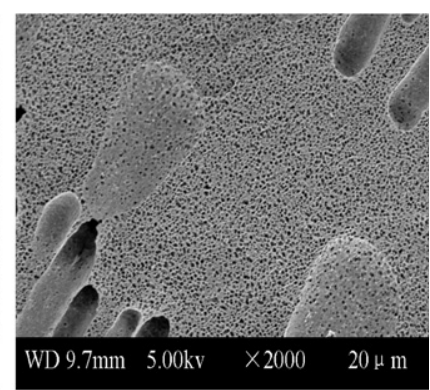

$\left(b_{3}\right)$

Fig. 3. SEM images of the PVDF membranes: $\left(a_{1}\right)$ inner surface of fresh membrane $(500 \times) ;\left(a_{2}\right)$ inner surface of fresh membrane $(2000 \times) ;\left(a_{3}\right)$ inner surface of the membrane after DCMD experiment; $\left(b_{1}\right)$ cross section of the fresh membrane $(500 \times) ;\left(b_{2}\right)$ cross section of the fresh membrane $(2000 \times)$; and $\left(b_{3}\right)$ cross section of the membrane after DCMD experiment. 
that no wettability phenomenon occurred. The observed initial permeate flux increase may also result from the dissolved gas transferring across the membrane when heated. Several preliminary experiments by our group have showed that soluble micro bubble may lead to an enhancement of permeate flux.

After the initial increase, a continual decline of the permeate flux was found. A large amount of deposit was found in the inlet of the membrane module (Fig. 4). A concentration decrease of $\mathrm{HCO}_{3}^{-}$from 9.25 to $1.43 \mathrm{mmol} \mathrm{L}^{-1}$ was found in the feed, what indicated the flux decline was associated with the formation of $\mathrm{CaCO}_{3}$, just as reported in other work [15]. The feed flow rate decreased from initial 0.60 to $0.45 \mathrm{~m} \mathrm{~s}^{-1}$ when the permeate flux decreased to $7.53 \mathrm{~kg} \mathrm{~m}^{-2} \mathrm{~h}^{-1}$ after $50 \mathrm{~h}$ running. So it can be assumed that the feed flow decrease caused by the deposit clogging was the main reason for the decrease of the module efficiency. It is because that the feed was pumped with magnetic pump; therefore, an increase of the feed flow resistance caused a decline of the flow rate. A decrease of the flow rate caused an unfavorable increase of the temperature polarization and comprises a possible reason of the observed

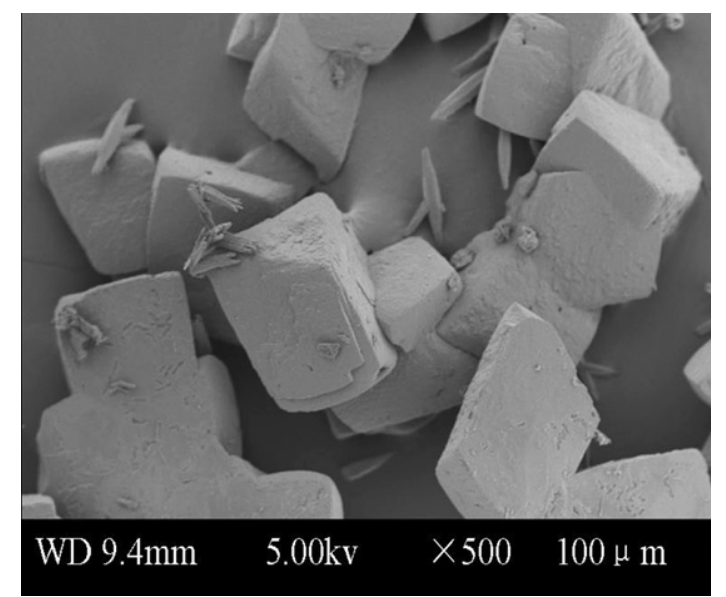

Fig. 4. SEM micrograph of $\mathrm{CaCO}_{3}$ deposit collected from the inlet of the module. reduction of the module efficiency [9]. The feed flow rate can be entirely restored by rinsing the module with $2 \% \mathrm{HCl}$. The permeate conductivity kept decline and stabilized at about $3.5 \mu \mathrm{s} \mathrm{cm}^{-1}$ at last, which indicated that the PVDF membrane exhibited a stable hydrophobicity.

The results presented in Fig. 2 (stage II) were obtained after the acidification of the PRO retentate. The solution $\mathrm{pH}$ was adjusted to 6.0. There was a sharp increase of the permeate conductivity at the beginning of the process. It was resulted from the $\mathrm{CO}_{2}$, which was not degassed completely after acidification, crossing the membrane to the permeate side. After the initial increase, the permeate conductivity was stabilized at about $3 \mu \mathrm{s} \mathrm{cm}^{-1}$. The problem of $\mathrm{CaCO}_{3}$ was alleviated by acidification, so the permeate flux declined only $20 \%$ after $200 \mathrm{~h}$ running after acidification (stage II). Then a sharp flux decline was observed. Up to the permeate flux decline, the PRO retentate was concentrated about 40 times as the initial concentration and the whole water recovery increased up to $98.8 \%$.

At high levels of water recovery, $\mathrm{CaSO}_{4}$ crystallization may take place when $\mathrm{Ca}^{2+}$ and $\mathrm{SO}_{4}^{2-}$ on the feed side exceed the solubility limit of $\mathrm{CaSO}_{4}$. Figure 5 illustrates the changes of $\mathrm{Ca}^{2+}$ and $\mathrm{SO}_{4}^{2-}$ during the process, which demonstrates the formation of $\mathrm{CaSO}_{4}$. Chernyshov et al. [16] used Lias and Govind method to model temperature and salt concentration distribution in membrane distillation feed channel and concluded that if the solubility of salt decreases with temperature, maximum supersaturation can occur in the bulk of the flow rater than at the membrane surface. Our previous research [26] proved that $\mathrm{CaCO}_{3}$ and $\mathrm{CaSO}_{4}$ were prone to precipitate in bulk solutions rather than at membrane surface, and $\mathrm{CaSO}_{4}$ precipitate can lead to a faster flux decline than $\mathrm{CaCO}_{3}$ precipitate. This phenomenon can be explained by the different morphology between them. $\mathrm{CaCO}_{3}$ has a hexagonal structure, and was more tenacious and compact; while $\mathrm{CaSO}_{4}$ 


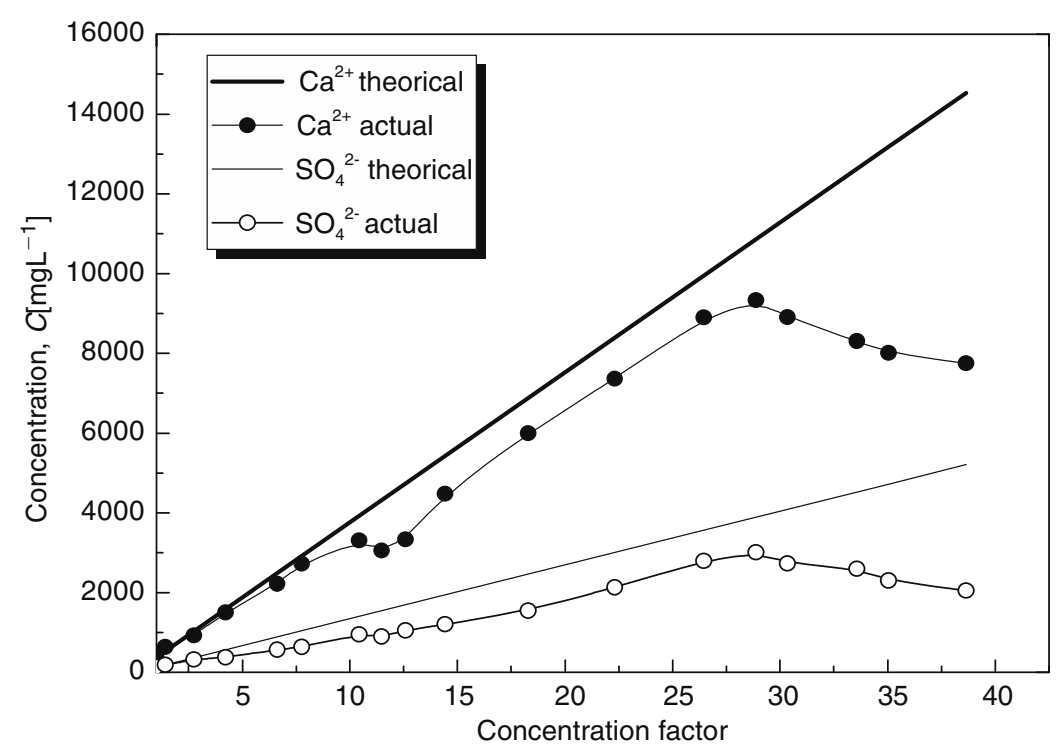

Fig. 5. Changes of $\mathrm{Ca}^{2+}$ and $\mathrm{SO}_{4}^{2-}$ concentration during DCMD process.

had a needle shape and was loosely attached [27]. So in the experiment, $\mathrm{CaCO}_{3}$ was found to attach to the feed container and the tubes, the probability of clogging the membrane module was decreased. While $\mathrm{CaSO}_{4}$ was found moving freely in the solution, once it formed, it would lead to a rapid clogging of the module, which would cause a sharp flux decline.

The feed PRO retentate $\mathrm{pH}$ was adjusted to 4.0 in stage III. Until the end of the process, the problem of scaling was eliminated just as reported in other works [19]. All the experiments mentioned above were at a laboratory scale, further research should be considered.

\subsection{DCMD process of silica bearing PRO retentate}

Additional $\mathrm{Na}_{2} \mathrm{SiO}_{3} .9 \mathrm{H}_{2} \mathrm{O}$ was added in $\mathrm{PRO}$ retentate, and the initial silica concentration of PRO retentate was $50 \mathrm{mg} \mathrm{L}^{-1}$. Permeate flux and conductivity is shown as a function of elapsed time in Fig. 6. The feed solution $\mathrm{pH}$ was adjusted to 6.0 at stage I. Along with the decomposition of $\mathrm{HCO}_{3}^{-}$when heated, the solution $\mathrm{pH}$ increased and stabilized at about 8.0. A lot of deposit was found in the inlet of the module. The EDS analysis of the deposit demonstrated that the deposit contained a large amount of $\mathrm{Si}, \mathrm{C}$ and $\mathrm{Ca}$ with a trace amount of $\mathrm{Mg}$. The deposit could be assumed as a mixture of $\mathrm{CaCO}_{3}$ and silicate. At alkaline $\mathrm{pH}$, silica may co-precipitate with soluble metals to form magnesium silicate $\left(\mathrm{Mg}_{2} \mathrm{SiO}_{4}\right)$ or calcium silicate $\left(\mathrm{Ca}_{2} \mathrm{SiO}_{4}\right)$. Furthermore, silica may be adsorbed onto the surface of insoluble metal hydroxide compounds, such as $\mathrm{Mg}(\mathrm{OH})_{2}$ or $\mathrm{MgCO}_{3}$ [18].

The feed solution $\mathrm{pH}$ was adjusted to 4.0 at stage II. The observed initial flux decline was due to the impurity clogging the module. After the washing of the module, the module efficiency recovered to the initial level. The performance kept stable until the PRO retentate was concentrated about 40 times. Then the sharp flux decline occurred. A large amount of deposit was found at the module inlet, while only a little deposit was found on the membrane surface. The EDS analysis (Fig. 7) showed the deposit was mainly 


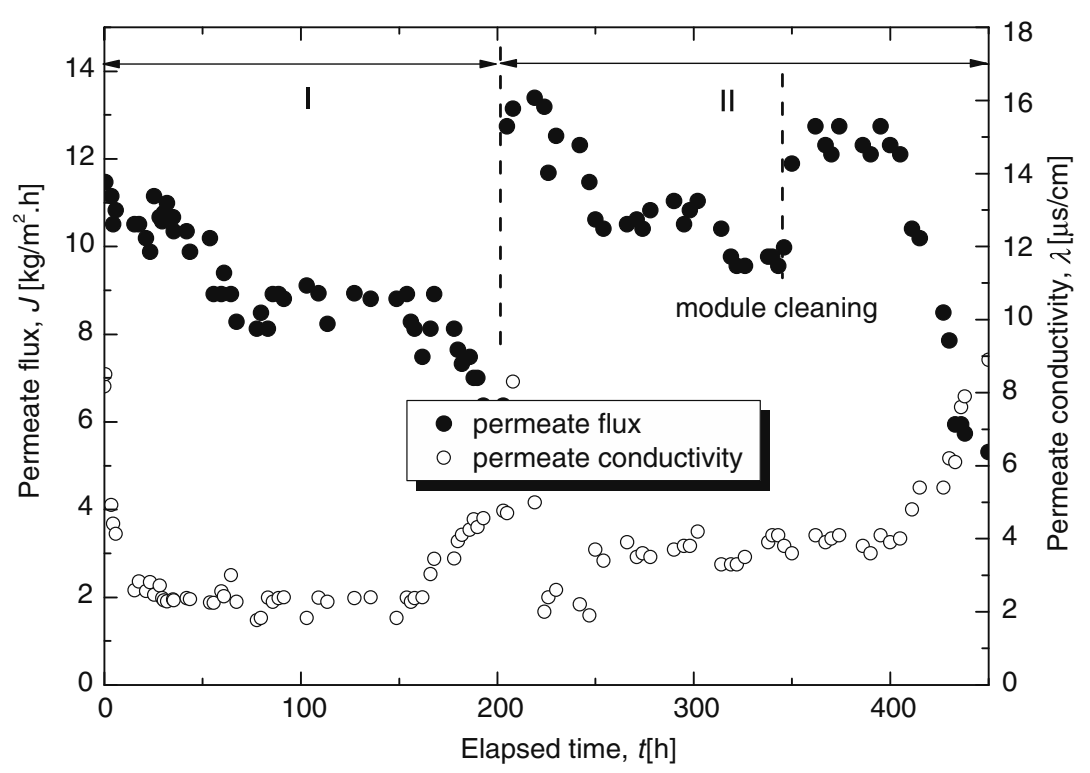

Fig. 6. Variation of the effciency during the DCMD process of silica bearing PRO.

consisted of $\mathrm{Si}, \mathrm{S}, \mathrm{C}, \mathrm{Ca}, \mathrm{Cl}, \mathrm{O}$ and a trace amount of $\mathrm{Cu}$ and $\mathrm{Mg}$. The deposit was assumed as a mixture of calcium scaling and colloid silica.

There are two relevant categories of silica fouling, namely precipitation fouling and particulate fouling. Precipitation is a glasslike scale formed on the surface due to concentration polarization. On the other hand, particulate fouling is the accumulation of colloids, formed initially in bulk solution or the boundary layer and then deposit on the membrane surface [19, 20, 23]. The silica fouling potential is dependent on the concentration of dissolved silica exceeding the amorphous silica equilibrium solubility of the solution. In RO processes, concentration polarization phenomenon is significant, so the silica concentration adjacent to the membrane surface is highly supersaturated; precipitation

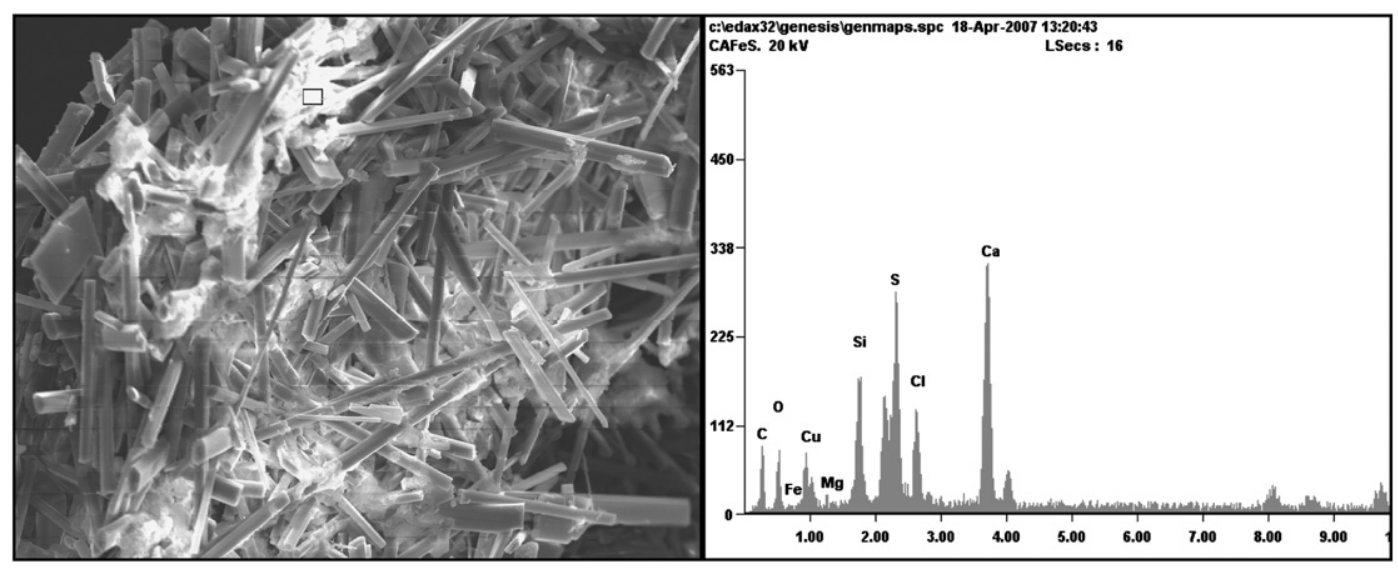

Fig. 7. SEM-EDS of the deposit collected from the module inlet. 
and particulate fouling were both common and then the initial silica feed concentration may affect the silica fouling [20].

However, during the DCMD process, temperature polarization phenomenon plays a more important role than concentration polarization in the heat and mass transfer process. So silica fouling phenomenon may be different from the pressure-driven membrane processes. Precipitation of monomeric silica on the membrane surface was not found during the process. The SEM analysis showed a mixture of colloid silica and calcium scaling formed during the process. It seem that particulate fouling occurred when the bulk silica concentration is high enough to reach the silica polymerize concentration. The further discussion about silica fouling during DCMD process should be investigated.

\subsection{DCMD process of iron and manganese bearing $P R O$ retentate}

Additional $\mathrm{FeCl}_{2} \cdot 6 \mathrm{H}_{2} \mathrm{O}$ and $\mathrm{MnCl}_{2} \cdot 4 \mathrm{H}_{2} \mathrm{O}$ were added to $\mathrm{PRO}$ retentate and the initial iron and manganese concentration of PRO retentate were kept at $1 \mathrm{mg} \mathrm{L}^{-1}$ and $0.5 \mathrm{mg} \mathrm{L}^{-1}$, respectively. The solution $\mathrm{pH}$ was adjusted to 6.0. As seen in Fig. 8, the permeate flux began to decline when the installation run $75 \mathrm{~h}$. It was found that the major reason of the observed permeate flux decline was the formation of the deposit at the inlet of the module. The SEMEDS analysis demonstrated that the deposit collected from the module inlet was mainly $\mathrm{Ca}, \mathrm{C}$ and $\mathrm{O}$, with a smaller amount of $\mathrm{Cl}$. It can be concluded that $\mathrm{CaCO}_{3}$ was still the main cause of the reduction of membrane efficiency and the influence of iron and manganese is not significant. An initial permeate conductivity increase due to the $\mathrm{CO}_{2}$ generated from acidification was observed, and then the permeate conductivity kept at a stable level. At the end of this process, the permeate conductivity increased, which was also found during the former experiments. One of the reasons causing an increase of permeate conductivity may be associated with the partial wetting phenomenon. Few larger pores which lead a low LEPw were still in

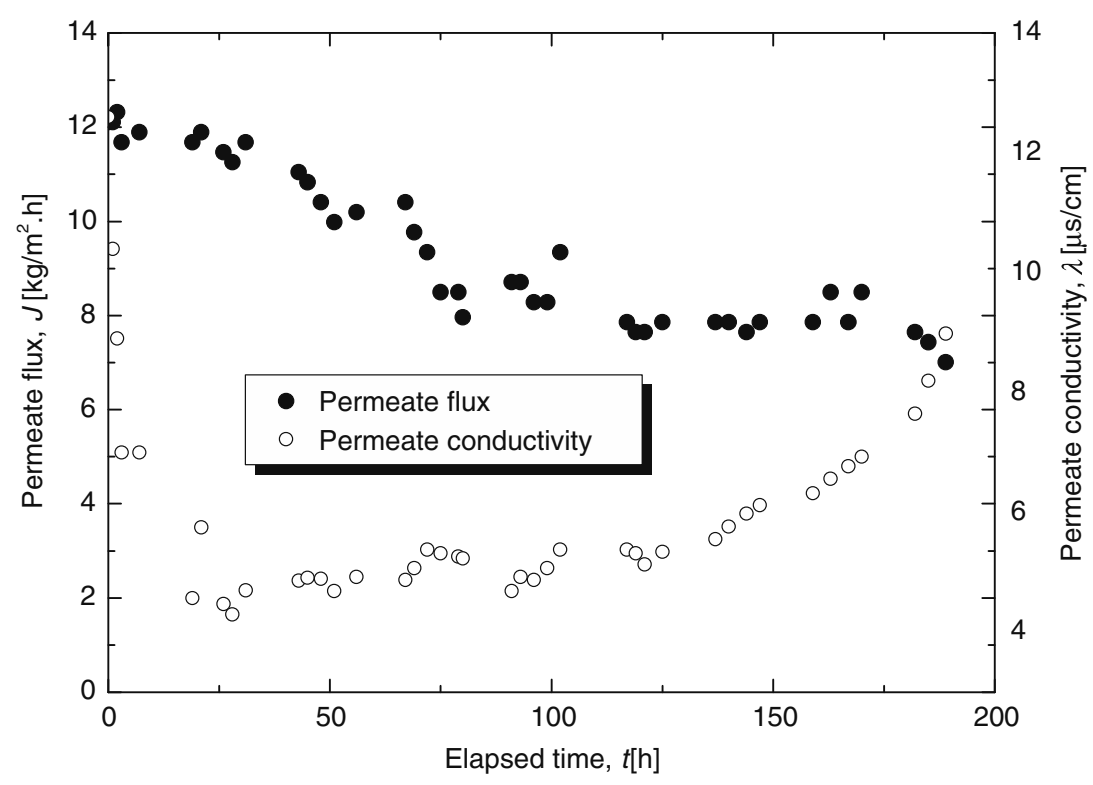

Fig. 8. Variation of the efficiency during DCMD process of high iron and manganese PRO retentate. 
existence, where ions can transfer directly across to the permeate side. During the DCMD process of low concentration solutions, with a constant permeate flux and low salinity, the permeate conductivity kept at about $3.0-3.5 \mu \mathrm{s} \mathrm{cm} \mathrm{cm}^{-1}$. But accompany with the flux decline and the feed salinity increase, partial wetting phenomenon became serious and lead to a slight permeate conductivity increase. Another reason was the hydraulic pressure on the feed side was slightly higher than that of the permeate side when the flow channel was clogged by the deposit, which additionally enhanced the possibility of leakage and consequently the permeate contamination.

All the experiments mentioned above were investigated at a laboratory level. Now, the pilot scale performance was being carried on the power plant for investigation. The stability and efficiency should be further considered.

\section{Conclusions}

The results of the present work have suggested that the PRO retentate (with the recovery $50 \%$ ) can be concentrated about 40 times by direct contact membrane distillation, and then the whole recovery has been significantly increased to $98.8 \%$. During the whole period of investigation, the PVDF membranes were found to be thermally stable and showed good separation characteristics.

Membrane fouling was investigated during the DCMD process. Feed flow decrease caused by the deposit clogging was the main reason for the reduction of module efficiency. A flow rate decrease would cause an unfavorable increase of the temperature polarization and lead to a reduction of the module efficiency. $\mathrm{CaSO}_{4}$ would lead to a sharper module efficiency decline than $\mathrm{CaCO}_{3}$ for their different structure and properties. Silica fouling was strongly influenced by the solution $\mathrm{pH}$. Silica may co-precipitate with soluble metals $\left(\mathrm{Ca}^{2+}\right.$ and $\left.\mathrm{Mg}^{2+}\right)$ to form silicate at alkaline solutions while colloid silica formed at acidic solutions. The influence of iron and manganese is not significant.

\section{Acknowledgment}

This work was supported by the National Key Technologies R\&D Program (Grant NO. 2006BAD01B02-02, Grant NO.2006BAJ08B00) and the National Natural Science Foundation of China (Grant NO. 50678169).

\section{References}

[1] C. Gavelich, T. Yun, B. Coffey and I.H. Suffet, Desalination, 154 (2003) 207-223.

[2] A. Rahardianto and J. Gaoa, J. Membr. Sci., 289 (2007) 123-137.

[3] K.W. Lawson and D.R. Lloyd, J. Membr. Sci., 124 (1997) 1-25.

[4] P. Peng, A.G. Fane and X. D. Li, Desalination, 173 (2005) 45-54.

[5] S.T. Hsu, K.T. Cheng and J.S. Chiou, Desalination, 143 (2002) 279-287.

[6] L. Martinez and F.J. Florido-Aiaz, Desalination, 137 (2001) 67-273.

[7] K.B. Petrotos and H.N. Lazarides, J. Food .Eng., 49 (2001) 201-206.

[8] C. H. Lee and W.H. Hong, J. Membr. Sci., 188 (2001) 79-86.

[9] M. Gryta, J. Membr. Sci., 265 (2005) 153-159.

[10] R. Sheikholeslami, Desalination, 167 (2004) 247-256.

[11] S. El-Manharawy, Desalination, $136 \quad$ (2001) 243-254.

[12] S. Lee, J. Kim and C.H. Lee, J. Membr. Sci., 163 (1999) 63-74.

[13] K. Karakulski, M. Gryta, Desalination, 177 (2005) 109-119.

[14] M. Gryta, K. Karakulski and M. Tomaszewska, Desalination, 200 (2006) 451-452.

[15] M. Gryta, M. Tomaszewska and A.W. Morawski, Inz. Chem. Proc., 22 (2001) 311-322.

[16] M.N. Chemyshov and G.W. Meindersma, Desalination, 157 (2003) 315-324.

[17] F. He, J. Gilron and H. Lee, J. Membr. Sci., 311 (2008) 68-80. 
[18] R. Sheikholeslami and J. Bright, Desalination, 143 (2002) 255-267.

[19] R. Sheikholeslami and S. Tan, Desalination, 126 (1999) 267-280.

[20] R. Sheikholeslami and S. Zhou, Desalination, 132 (2000) 337-344.

[21] T. Koo, Y.J. Lee and R. Sheikholeslami, Desalination, 139 (2001) 43-56.

[22] R. Sheikholeslami, I.S. Al-Mutaz and S. Tan, Desalination, 150 (2002) 85-92.
[23] P. Sahachaiyunta, T. Koo and R. Sheikholeslami, Desalination, 144 (2002) 373-378.

[24] F.N. Karelin, Desalination of water by Reverse Osmosis.Stroyizsat, Moscow, 1988.

[25] A.M. Barbe, P.A. Hogan and R.A. Johnson, J. Membr. Sci., 172 (2000) 149-156.

[26] D. Qu, J. Wang, B. Fan, Tech. Water Treatment, 33 (2007) 14-17.

[27] R. Sheikholeslami, Desalination, 154 (2003) 117-127. 